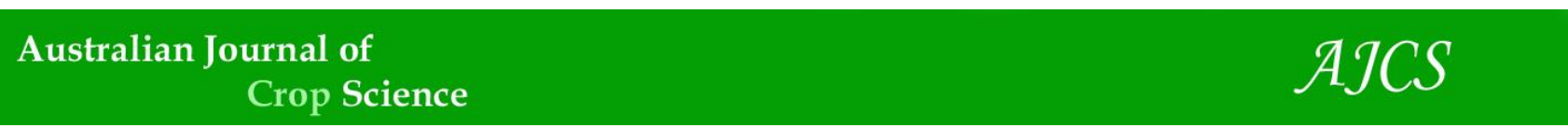

AJCS 15(04):531-537 (2021)

ISSN:1835-2707

doi: 10.21475/ajcs.21.15.04.p2806

\title{
Complex soil contamination severely impacts seed-sown crop viability in Australia
}

\author{
Annaclaire G. McDonald, Brad R. Murray, Daniel W. Krix, Megan L. Murray* \\ School of Life Sciences, University of Technology Sydney, PO Box 123, NSW 2007 Australia
}

*Corresponding author: Megan.Murray@uts.edu.au

\begin{abstract}
Food security is a critical issue for many global communities. Heavy metal contamination in soils present a major and ongoing ecological risk associated with human activities which may impact the viability and safety of seed-sown crops. To better understand the impacts of soil contamination by heavy metals on seed-sown crop viability, we examined germination responses of eight commercially-important fruit and vegetable crop species to copper, zinc, and lead contamination at levels likely to be found in contaminated regions in Australia. We compared the germination attributes of days to first germination, germination period, and total proportion of seeds germinated under concentration limits of heavy metals detected at degraded sites and current Australian

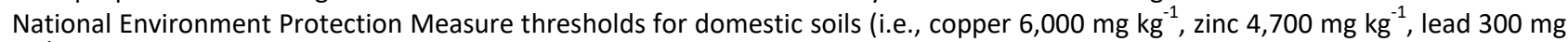
$\mathrm{kg}^{-1}$ ). The combined heavy metal treatment (i.e. all three metals) significantly inhibited germination for all edible crop species with only carrots able to germinate under complex, multi-metal-contaminated conditions. Seed viability was significantly decreased in mulberry ( $M$. alba var. tatarica, $M$. nigra, and $M$. rubra) and lettuce (L. sativa), with lowered seed germination in all metals compared to carrot (D. carota), radish (R. sativus), tomato (S. lycopersicum) and common bean ( $P$. vulgaris). These results indicate heavy metal contamination is a notable risk to seed-sown crop species, with multi-metal contamination events likely to be severely damaging to lettuce, tomato, radish, common bean, and mulberry crops.
\end{abstract}

Keywords: Food security; heavy metals; land contamination; agriculture; urban gardening.

\section{Introduction}

Land contamination is an ongoing threat to food security around the globe (Wang et al., 2005; European Union 2006; Rickson et al., 2015; Rojas et al., 2016). Heavy metals such as copper, zinc, and lead are of great concern with respect to their worldwide distribution as soil pollutants, detrimental impacts on crop species and subsequent health risks to humans and other organisms exposed to these contaminant pathways (Duruibe et al., 2007; Jennings 2013; Kooner et al., 2014; Tóth et al., 2016). In many instances some of the most arable lands for growing crops for human consumption are those that have also been highly suitable for mining of nonrenewable resources such as heavy metals (Langkamp 1985; Lechner et al., 2016). The contaminant legacies of these mining practices can potentially pose a serious risk to human health if these lands are used for growing edible crops (Alam et al., 2003; Roy and McDonald 2015). Unfortunately, farmers in developing nations may have little choice but to use contaminated landscapes and risk food contamination given the climatic and spatial limitations to landscapes where key food crops can be produced (Xiao et al., 2017).

Similar safety concerns are relevant for domestic food gardens, especially in urban cities where edible plants, including crop species, may be grown in positions exposed to soil and airborne pollutants from industrial processes, road traffic, historical use of leaded petrol, and corrosion of building materials (Finster et al., 2004; Clark et al., 2006; Antisari et al., 2015; Rouillon et al., 2017). For example, 88\% of urban garden soils tested by Clark et al. (2006) in
Massachusetts, USA, contained lead levels over the reported US EPA threshold of $400 \mathrm{mg} \mathrm{g}^{-1}$. Similarly, in Kano, Nigeria, urban crop species were discovered to contain levels of zinc in vegetables well above the WHO/FAO guideline at that time (Nafiu et al., 2011). Recent investigations of the soil lead content of domestic gardens in Australia revealed $40 \%$ of participating Sydney homes exceeded the recommended guideline level for residential soils (Rouillon et al., 2017; NEPM 2013). This is important to note as urban communities are increasingly embracing guerrilla gardening and home gardening trends (Iveson 2013; Antisari et al., 2015).

Seed germination is a critical life-history stage in plant survival and establishment that can affect later growth, function and plant health (Phillips and Murray 2012; Márquez-García et al., 2013; Sánchez-Rendón et al., 2017). Understanding the germination requirements of edible crop species in relation to contaminants such as heavy metals in particular is of vital importance considering the widespread problem of complex soil contamination (Sethy and Ghosh 2013; Sánchez-Rendón et al., 2017). This is especially important from an agricultural management perspective where specific crop species may unfortunately be restricted to cultivation in suboptimal landscapes that have a history of heavy metal contamination (García-Gómez et al., 2018). In the case of urban gardens, gardeners who direct-seed crops into contaminated soils could unknowingly be experiencing contaminant related inhibition of germination (Xiong 1998). Furthermore, from an ecological perspective, an understanding of the effects of heavy metal pollution on seed germination can help to inform broader knowledge of 
plant population dynamics, seed dispersal, frugivory and a range of life-history and ecological features (Robertson et al., 2006).

In the present study, we investigated the effects of the heavy metals copper, zinc and lead on the germination of seeds of eight edible fruit and vegetable species (Table 1). The species span a wide variety of plant genera from six taxonomic families and range from common crop species used in domestic gardens (Phaseolus vulgaris, Raphanus sativus, Lactuca sativa, Daucus carota, Solanum lycopersicum) to exotic fruit species (Morus nigra, Morus rubra, Morus alba var. tatarica). Previous studies investigating germination effects of heavy metals lead and cadmium on $P$. vulgaris show that the species is capable of germinating in concentrations up to $500 \mathrm{mg} \mathrm{kg}^{-1}$ at the cost of average root length, moisture content and germination rate compared to lower level contaminant exposure (Glasgow, 2018). Very low thresholds (0 to $1024 \mu \mathrm{M}$ ) of lead, cadmium, nickel and copper have been found to have no significant effect on germination of $R$. sativus, $L$. sativa, $D$. carota and S. lycopersicum (Di Salvatore et al., 2008). Limited knowledge exists for seed germination responses of Moraceae species to heavy metal contaminants. With this in mind, we compared the germination responses of these eight species to the presence of copper, zinc and lead using concentrations of these heavy metals reported at degraded sites and current National Environment Protection Measure (NEPM) thresholds for domestic soils (i.e. copper 6,000 mg $\mathrm{kg}^{-1}$, zinc 4,700 $\mathrm{mg} \mathrm{kg}^{-1}$, lead $300 \mathrm{mg} \mathrm{kg}^{-1}$ ).

Copper thresholds of $6,000 \mathrm{mg} \mathrm{kg}^{-1}$ have been found in soils at Dolfrwynog Bog, a former copper mine in North Wales, UK (Brewin et al., 2007). Putting Australian guidelines into perspective, this figure coincides with the recommended level for residential soils containing homegrown produce in Australia (NEPM 2013). Soils in proximity to areas of car battery salvaging in Denmark were found to contain 6,600 $\mathrm{mg} \mathrm{kg}^{-1}$ of copper while $4,700 \mathrm{mg} \mathrm{kg}^{-1}$ of zinc was associated with activities of scrap metal cutting (Jensen et al., 2000). Zinc concentrations of $4,700 \mathrm{mg} \mathrm{kg}^{-1}$ have also been found in dredged sediments of historic smelting regions of France (Panfili et al., 2005) and were discovered in multi-elemental dust deposition on residential shelves and public building entrances as a result of coke oven use in County Durham, England (Davenport 1953). Recently, lead concentrations over $300 \mathrm{mg} \mathrm{kg}^{-1}$ have been detected in $21 \%$ of tested Melbourne home vegetable gardens, Australia (Laidlaw et al., 2018). Lead at $300 \mathrm{mg} \mathrm{kg}^{-1}$ is the current health investigation level (HIL) for residential soils in Australia (NEPM 2013). Thus, these heavy metal thresholds were chosen for this study because they are highly conservative when compared to international agricultural and domestic guidelines (Jennings 2013; Rouillon et al., 2017) and therefore germination observed in these conditions informs likely success in lower thresholds globally.

Because contamination events are often characterized by a combination of heavy metals within the soil profile (da Rosa et al., 2018), we not only examined the effect of each heavy metal on its own, but also compared these effects with germination responses to a combination of all three metals. Combinations of heavy metals have the potential to increase phytotoxicity as plants are subjected to multiple stress responses and higher concentrations of contaminants overall. Important to the predictions we test below, previous work has shown that alteration to plant function and chlorosis effects are more pronounced in species exposed to excess copper compared with zinc (Ivanova et al., 2010). In addition, while copper and zinc are both essential elements in trace concentrations, lead has no biological function (Alvarado-López et al., 2019). To our knowledge, germination success of mulberry species in heavy metals copper, lead and zinc has yet to be investigated. Furthermore, seed germination responses to Australian guideline levels of lead have yet to be tested in these crop species. We tested three predictions: (1) seed germination will be inhibited by the presence of each heavy metal; (2) inhibition of seed germination will be greatest to least in the following order of the three metals: copper > lead > zinc > no contaminant; and (3) a combination of all three metals in soils will have the greatest overall effect on seed germination.

\section{Results}

\section{Germination inhibition}

We found that seed germination was completely inhibited by the combined heavy metal treatment in seven of the eight study species including bean, lettuce, the three mulberry species, radish and tomato (Fig. 1). We also found complete germination inhibition in lettuce in response to the $\mathrm{Cu}$ and $\mathrm{Zn}$ treatments, no germination in bean and black mulberry in response to $\mathrm{CU}$ and no germination in red mulberry to $\mathrm{Zn}$ (Fig. 1).

\section{Germination onset}

There was a significant treatment $x$ species interaction for germination onset $(\chi 2=39.30, D F=16, P=0.001)$ with significant treatment $(\chi 2=272.40, D F=4, P<0.0001)$ and species ( $\chi 2=435.06, D F=7, P<0.0001)$ effects. We found that carrot germination onset was most heavily impacted by heavy metal contamination, with significant delays in germination in response to $\mathrm{Cu}, \mathrm{Zn}$ and the combined heavy metal treatment (Fig. 1). In addition, the effect of $Z n$ was to significantly delay germination in both black mulberry and Russian mulberry, while Cu significantly delayed germination in Russian mulberry and radish (Fig. 1).

\section{Germination duration}

A significant treatment $x$ species interaction emerged for germination duration $(X 2=128.60, D F=16, P \quad 0.0001)$ with significant treatment $(\chi 2=17.35, D F=4, P<0.0001)$ and species ( $\chi 2=200.27, D F=7, P<0.0001$ ) effects. Germination duration was significantly reduced in red mulberry by $\mathrm{Cu}$ and $\mathrm{Pb}$ and in Russian mulberry by $\mathrm{Cu}$ and $\mathrm{Zn}$ (Fig. 1). In contrast, germination duration was significantly extended in carrot by $\mathrm{Zn}$ and $\mathrm{Pb}$ (Fig. 1).

\section{Total germination}

There was a significant treatment $x$ species interaction for total germination $(X 2=114.19, D F=28, P<0.0001)$ with significant treatment $(X 2=513.94, D F=4, P<0.0001)$ and species $(X 2=334.82, D F=7, P<0.0001)$ effects. Total germination was significantly reduced in carrot by each of the $\mathrm{Cu}, \mathrm{Zn}$ and $\mathrm{Pb}$ treatments as well as the combined treatment (Fig. 1). The $\mathrm{Zn}$ treatment significantly reduced the number of seeds germinating in bean, Russian mulberry, radish and tomato (Fig. 1). The $\mathrm{Cu}$ treatment significantly reduced seed germination in Russian mulberry and radish (Fig. 1). 
Table 1. Study species used in the experiments to assess seed germination responses to copper, zinc and lead contamination. Solanum lycopersicum has been grouped with vegetables commonly grown in domestic gardens because many domestic growers consider it a vegetable crop based on its culinary function (Bergougnoux 2014).

\begin{tabular}{lllll}
\hline Taxonomic Family & Common name & Scientific Name & Classification & Seed Origin \\
\hline Apiaceae & Carrot & Daucus carota L. & Vegetable & Australia \\
Asteraceae & Lettuce & Lactuca sativa L. & Vegetable & Australia \\
Brassicaceae & Radish & Raphanus sativus L. & Vegetable & Australia \\
Fabaceae & Common Bean & Phaseolus vulgaris L. & Vegetable & Australia \\
Moraceae & Russian Mulberry & Morus alba var. tatarica L. & Fruit & USA \\
Moraceae & Black Mulberry & Morus nigra L. & Fruit & Australia \\
Moraceae & Red Mulberry & Morus rubra L. & Fruit & USA \\
Solanaceae & Tomato & Solanum lycopersicum L. & Vegetable & Australia \\
\hline
\end{tabular}

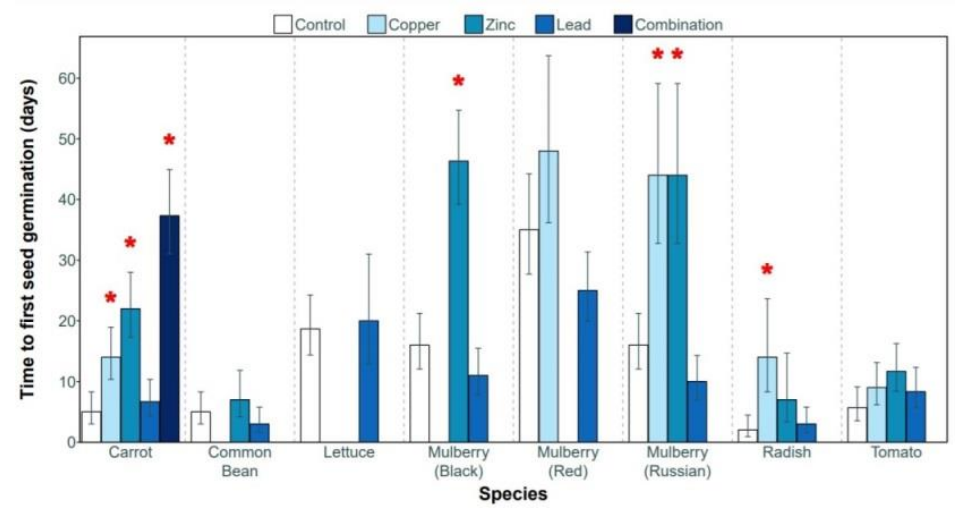

Fig 1. Germination onset across the eight study species in relation to the heavy metal treatments (mean $+\mathrm{SE}$ ). An asterisk shows those treatments that differed significantly $(P<0.05)$ from the uncontaminated control within each species.

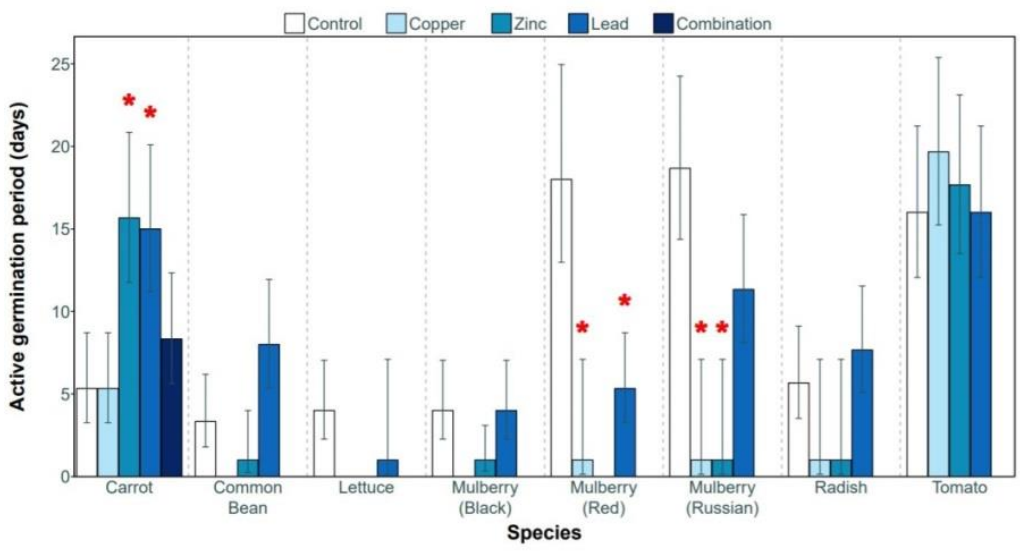

Fig 2. Germination duration across the eight study species in relation to the heavy metal treatments (mean $+\mathrm{SE}$ ). An asterisk shows those treatments that differed significantly $(P<0.05)$ from the uncontaminated control within each species.

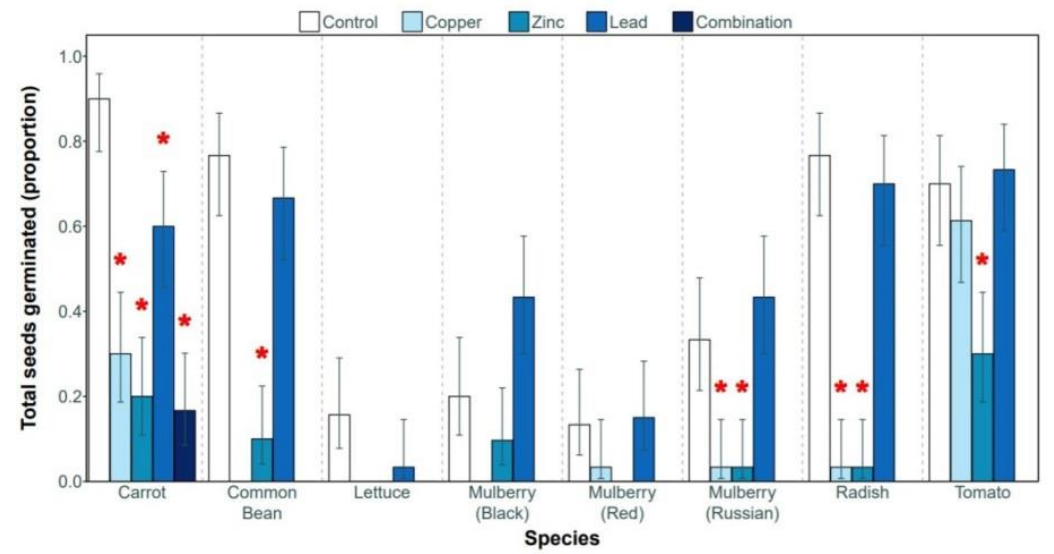

Fig 3. Total germination across the eight study species in relation to the heavy metal treatments (mean $+\mathrm{SE}$ ). An asterisk shows those treatments that differed significantly $(P<0.05)$ from the uncontaminated control within each species. 


\section{Discussion}

Germination inhibition from heavy metal salts can manifest in a variety of physiological and biochemical stressors including instability to membranes, genomic structure, enzyme activity, oxidative stress, as well as metabolism and nutrient loss (Sethy and Ghosh 2013). It follows that the greatest occurrence of germination inhibition arose in the combination treatment where seeds were exposed to the highest toxicity potential. This treatment also had a higher concentration of both sulphate and nitrate salts that can induce salinity related osmotic or ionic stressors contributing to overall toxicity (Manzoor et al., 2017). However, enrichment with nitrate salts has also previously been linked to promoting germination success (Hendricks and Taylorson 1974). Relevant to the context of this study, instances of heavy metal contamination events are related to increased soil salinity and associated adverse effects on plants (Byeong et al., 2011; Sethy and Ghosh 2013).

In this study, we found that individual crop species had statistically different germination responses to each heavy metal treatment with overall patterns not consistently predictable by treatment or species groups. Smaller group patterns indicate germination inhibition from heavy metals with potential for further studies to investigate specific thresholds of inhibition for these species using greater seed quantities. For example, the three species from taxonomic family Moraceae recorded a delay in onset of germination in copper (M. alba var. tatarica and $M$. rubra) and zinc treatments ( $M$. alba var. tatarica and $M$. nigra). This taxonomic family took approximately twice as long as the other species to germinate in copper and zinc treatments with very little overall germination recorded in these treatments if at all (Fig. 1; Fig. 3). Comparing these results to control dishes could suggest a sensitivity of these species to copper and zinc heavy metal pollution however a greater sample would be required to confirm this.

Mulberries (Morus spp.) have a wide range of uses including a pivotal role in supporting economically and culturally significant silk trades across Asia (Maji et al., 2005; SánchezRendón et al., 2017). The species boasts antioxidant rich fruits and numerous traditional Chinese remedies from improving eyesight to treating premature grey hair (Zhang et al., 2018). Aside from its acclaimed health benefits it has also demonstrated robustness to heavy metal contamination and in some cases phytoremediation abilities (Olson and Fletcher 1999; Rezek et al., 2009). Recent research has reported that a mulberry plant's sex can play a role in its tolerance to multi-contaminant effects. It was found that lead induced stress on $M$. alba saplings is reduced in the presence of zinc with this reduction observed further in female saplings when compared to males (Qin et al., 2018). This multi-contaminant effect has yet to be investigated on germination of mulberry seeds and could be a further line of enquiry for much lower heavy metal concentrations than those used in this study.

Carrot and tomato had the most success across treatments with carrot demonstrating to be the only species able to germinate under combination treatments (Fig. 3). As a root vegetable capable of assisted lead accumulation (AlvaradoLópez et al., 2019), this has implications for crop growers and domestic food safety as carrots will tolerate growing in contaminated soils where metals may compartmentalise into their edible tissues. Important to crop cultivation, the timeframe for germination onset in carrots may be variable in lead and zinc treatments limiting predictability in germination success for growers. These treatments increased the active germination period in Carrots compared to controls where metal stress may have delayed germination onset of some seeds within the same dishes (Fig. 2).

Radishes and common beans germinated within days in control dishes but were stunted in copper and combination treatments in line with our earlier predictions. It is well documented that excess copper induces stress related growth inhibition in plants (Lequeux et al., 2010; Feigl et al., 2013; Nair and Chung 2015). Copper related germination suppression was experienced across all species except for tomato where copper treatments did not differ from control treatments. In their investigation of vegetable seed germination and root elongation, Di Salvatore et al. (2008) tested seeds in comparatively low concentrations (0 to 1024 $\mu \mathrm{M})$ of $\mathrm{Cd}, \mathrm{Pb}, \mathrm{Ni}$ and $\mathrm{Cu}$ finding that there was no significant effect of metals on germination. However, their results for root elongation tests noted that tomatoes were more sensitive to copper than radishes, despite no significant effect to germination success. The sensitivity of lettuce was replicated in this experiment. However, the difference in dose led to a reverse response of greater root growth in 2 $\mu \mathrm{M}$ of copper. Finally, the authors discuss the resistance of radishes in their root elongation tests to lead treatments. Radishes may exhibit greater resistance to low lead and copper exposure but transition to mechanisms of tolerance in higher concentrations (Gadd 1993; McLaughlin et al., 2000). This comparison denotes a further line of inquiry given the absence of root elongation measurements in this experiment.

Australian residential guideline levels of copper and lead were tested in this experiment as a conservative approach to evaluating germination inhibition in heavy metal contaminated soils. However, it is important to note that these levels are based on total concentrations (mg kg ${ }^{-1}$ ) (NEPM 2013). The levels include leeway for non-bioavailable quantities of each metal that are inevitably present in soils as some metal constituents are immobilised into safer forms when they bind to matter present in the soil (Gadd 1993). Furthermore, agar media suspends seeds in concentrations where entire seed coats are subjected to the target concentration contributing to higher surface area potential for absorption and therefore toxicity than what would occur in soils (Di Salvatore et al., 2008). Testing seeds for final heavy metal concentrations post-experiment would assist in confirming exact concentrations species were subjected to. The germination patterns from the edible species tested in this study are noteworthy as they indicate that different groups of species respond with their own mechanisms to concentrated levels of heavy metal pollution in their environments.

\section{Materials and Methods}

\section{Study species}

The 8 species selected for the study (Table 1 ) are all readily accessible as crop species and affordable for domestic garden growers. Vegetable species were further selected based on their common occurrence in domestic and urban vegetable gardens. We included mulberries (Morus spp.) in particular because they have demonstrated heavy metal robustness in previous work (Rafati et al., 2011) but have yet to be tested at Australian residential guideline levels. Fresh seeds of the fruit species $M$. nigra were purchased from the 
Australian seed seller OleLantana and Fair Dinkum Seeds, located in Toowomba and Gin Gin, Queensland. Seeds of the other two fruit species (M. rubra and $M$. alba var. tatarica) were purchased from the USA (TreeSeeds.com). Seeds of the five vegetable species (Table 1) were purchased from a local nursery Honeysuckle Garden in Mosman, Sydney.

\section{Experimental design and procedure}

To determine the impacts of heavy metal contamination on seed germination we performed experiments that targeted each heavy metal on its own as well as including a treatment that represented a combination of all three heavy metals. Experimental treatments for seed germination consisted of agar media in standard Petri dishes spiked with either (i) copper sulphate $\left(\mathrm{CuSO}_{4}\right.$ ) (Anhydrous form, LR grade, 98\% purity, Chem-Supply Pty Ltd, Australia), (ii) zinc nitrate $\left(\mathrm{Zn}\left(\mathrm{NO}_{3}\right)_{2} 6 \mathrm{H}_{2} \mathrm{O}\right)$ (Hexahydrate form, AR grade, 99\% purity, Chem-Supply Pty Ltd, Australia), (iii) lead nitrate $\left(\mathrm{Pb}\left(\mathrm{NO}_{3}\right)_{2}\right)$ (AR grade, 99\% purity, Chem-Supply Pty Ltd, Australia) or (iv) a combination of all three heavy metals. We also included an uncontaminated agar control set of Petri dishes. There were three replicate Petri dishes for each experimental treatment per species, with 10 seeds placed in each dish. Final agar concentrations of copper $\left(6,000 \mathrm{mg} \mathrm{kg}^{-1}\right)$, zinc $\left(4,700 \mathrm{mg} \mathrm{kg}^{-}\right.$ $\left.{ }^{1}\right)$, and lead (300 mg kg${ }^{-1}$ ) were derived from levels previously detected at degraded sites and current Australian residential soil guidelines based on total mass (NEPM 2013). The combination treatment was spiked with copper 6,000 $\mathrm{mg} \mathrm{kg}^{-1}$, zinc 4,700 $\mathrm{mg} \mathrm{kg}^{-1}$, and lead $300 \mathrm{mg} \mathrm{kg}^{-1}$.

Agar was made in $500 \mathrm{ml}$ batches using a temperaturecontrolled heat pad and thermocouple (VELP AREC.X, Italy) and $5 \mathrm{~g}$ of bacteriological grade (LR) agar powder (ChemSupply Pty Ltd, Australia) measured using analytical scales (Sartorius A-120S analytic, Australia). Contaminant masses were determined by calculating the relative atomic mass of each compound's constituents to find the proportion of the target contaminant. The desired concentration was divided by this proportion to obtain the amount required in grams. These equated to $10.6925 \mathrm{~g}$ of zinc nitrate, $7.5350 \mathrm{~g}$ of copper sulphate and $0.2398 \mathrm{~g}$ of lead nitrate per $500 \mathrm{ml}$ of agar. The heat pad was maintained below boiling point at $90^{\circ} \mathrm{C}$.

Seeds were vacuum cleaned in a vacuum filtering flask with a sidearm hose and loosely fitted cork prior to germination experiments. A single drop of detergent and $1 \mathrm{ml}$ of bleach were added to $200 \mathrm{ml}$ of milli-Q water in the flask. Species groups of seeds were vacuum cleaned for 15 to 20 minutes. The seeds were drained into a pre-autoclaved tea strainer and rinsed lightly with ethanol (undenatured AR grade, 99.5\% purity, Chem-Supply Pty Ltd, Australia). Petri dishes were made up in a class II biological safety cabinet (Gelaire Pty Ltd, Australia, SFT 212 DTT model) to reduce contamination from laboratory air. Dishes were double bagged in plastic ziplocks to prevent contamination and moisture loss and then positioned on benches in the glasshouse at The University of Technology, Sydney where they received natural light and dark cycles for the duration of the experiment. Cycling of light and dark conditions has previously proved beneficial for seed response compared to single light level exposure (Aamlid and Arntsen 1998).

Observations of germination were recorded twice week for nine weeks. Germination was defined as the point where the radicle visibly emerged from the seed coating. Seeds that had not germinated by completion of the experiment were monitored until a state of decomposition was reached where there was no further possibility of germination (Phillips and Murray 2012).

\section{Statistical analyses}

We used an ANOVA approach via the implementation of separate generalised linear models (Crawley 2012) to determine the impacts of heavy metal contamination on seed germination. The response variable in each model was either germination onset (the time taken for seeds to begin to germinate), germination duration (the period of time over which seeds germinated) or total germination (the total proportion of seeds that germinated). There were two categorical explanatory variables in all models which included heavy metal treatment and species. Treatment had five levels including each of the three individual contaminants, the combined treatment with all contaminants and the uncontaminated control group and species had eight levels with one for each species. The treatment $x$ species interaction was included in all models, with a significant interaction in models demonstrating variation among species in the type of effects of the heavy metals. Mean values of the three replicates per species were used in the models. Because the data were in the form of counts, we used a Poisson error structure with a logit link for germination onset and germination duration generalised linear models. We used a quasibinomial model to account for overdispersion in the total germination model. Significant ANOVA results were followed by post-hoc pairwise tests (with $\mathrm{P}$ value adjustment for multiple testing; Benjamini and Hochberg 1995) to determine significant contrasts between heavy metal treatments and the uncontaminated control. All statistical analyses were performed using $R$ statistical software ( $R$ core team 2019) through R Studio (Version 3.5.1) and the emmeans package post-hoc tests (Lenth 2019).

\section{Conclusion}

This study investigated seed response of eight edible crop species to five levels of heavy metal treatments. Species and treatment groups did not consistently predict rates of germination across all species. However, a combination of copper, zinc and lead greatly inhibited germination with only one crop (i.e., carrot) able to germinate under these conditions. We suggest that carrots pose the highest risk to crop growers who direct-seed this species into complex, multi-element metal contaminated sites.

\section{Acknowledgments}

This work was supported by an Australian Research Training Program Scholarship. The authors wish to thank Gemma Armstrong for her technical assistance with this project.

\section{References}

Alam MGM, Snow ET, Tanaka A (2003) Arsenic and heavy metal contamination of vegetables grown in Samta village, Bangladesh. Sci Total Environ. 308:83-96.

Alvarado-López CJ, Dasgupta-Schubert N, Ambriz JE, Arteaga-Velazquez J, Villegas JA (2019) Lead uptake by the symbiotic Daucus carota L.-Glomus intraradices system and its effect on the morphology of extra- and intraradical fungal microstructures. Environ Sci Pollut Res. 26:381-91. 
Aamlid TS, Arntsen D (1998) Effects of light and temperature on seed germination of Poa pratensis from high latitudes. Acta Agr Scand B-S P. 48:239-47.

Antisari LV, Orsini F, Marchetti L, Vianello G, Gianquinto G (2015) Heavy metal accumulation in vegetables grown in urban gardens. Agron Sustain Dev. 35:1139-47.

Benjamini $Y$, Hochberg $Y$ (1995) Controlling the false discovery rate: a practical and powerful approach to multiple testing. J R Stat Soc Series B Stat Methodol. 57:289-300.

Bergougnoux V (2014) The history of tomato: From domestication to biopharming. Biotechnol Adv. 32:170-89.

Brewin LE, Mehra A, Lynch PT, Farago ME (2007) Bioavailability of copper within Dolfrwynog Bog soils, North Wales, UK. Chem Spec Bioavailab. 19:149-62.

Byeong YP, Jae KL, Hee MR, Kim YH (2011) Effects of heavy metal contamination from an abandoned mine on tomato growth and root-knot nematode development. Plant Pathol J. 27:266-71.

Clark HF, Brabander DJ, Erdil RM (2006) Sources, sinks, and exposure pathways of lead in urban garden soil. J Environ Qual. 35:2066-74.

Crawley MJ (2012) The R Book, 2nd Ed. John Wiley and Sons Ltd.

da Rosa GM, Gabriel M, Wastowski AD, da Rosa RS (2018) Behavior of copper and zinc metals in soil profile, submitted to different sources of fertilization. Environ Qual Manag. 28:89-93.

Davenport SJ (1953) Review of literature on health hazards of metals: copper, vol 1. U.S. Department of the Interior, Bureau of Mines, USA.

Di Salvatore M, Carafa AM, Carratù G (2008) Assessment of heavy metals phytotoxicity using seed germination and root elongation tests: A comparison of two growth substrates. Chemosphere. 73:1461-4.

Duruibe JO, Ogwuegbu MOC, Egwurugwu JN (2007) Heavy metal pollution and human biotoxic effects. Int J Phys Sci. 2:112-8.

European Union (EU) (2006) Commission regulation (EC) No. $1881 / 2006$. Setting maximum levels for certain contaminants in foodstuffs. Official Journal of the European Union. 364:5-24.

Feigl G, Kumar D, Lehotai N, Tugyi N, Molnar A, Oerdoeg A, Szepesi A, Gemes K, Laskay G, Erdei L, Zsuzsanna K (2013) Physiological and morphological responses of the root system of Indian mustard (Brassica juncea L. Czern.) and rapeseed (Brassica napus L.) to copper stress. Ecotoxicol Environ Saf. 94:179-89.

Finster ME, Gray KA, Binns HJ (2004) Lead levels of edibles grown in contaminated residential soils: a field survey. Sci Total Environ. 320:245-57.

Gadd GM (1993) Interactions of fungi with toxic heavy metals. New Phytol. 124:25-60.

García-Gómez C, Obrador A, González D, Babín M, Fernández MD (2018) Comparative study of the phytotoxicity of ZnO nanoparticles and $\mathrm{Zn}$ accumulation in nine crops grown in a calcareous soil and an acidic soil. Sci Total Environ. 644:770-80.

Glasgow G (2018) Synergistic effect of cadmium (Cd) and lead $(\mathrm{Pb})$ on Phaseolus vulgaris seed germination and physiology. ProQuest Dissertations and Theses. Michigan, USA.

Hendricks SB, Taylorson RB (1974) Promotion of seed germination by nitrate, nitrite, hydroxylamine, and ammonium salts. Plant Physiol. 54:304-9.
Ivanova EM, Kholodova VP, Kuznetsov VV (2010) Biological effects of high copper and zinc concentrations and their interaction in rapeseed plants. Russ J Plant Physiol. 57:80614.

Iveson K (2013) Cities within the city: Do-it-yourself urbanism and the right to the city. Int J Urban Reg Res. 37:941-56.

Jennings AA (2013) Analysis of worldwide regulatory guidance values for the most commonly regulated elemental surface soil contamination. J Environ Manage. 118:72-95.

Jensen DL, Holm PE, Christensen TH (2000) Soil and groundwater contamination with heavy metals at two scrap iron and metal recycling facilities. Waste Manag Res. 18:52-63.

Kooner R, Mahajan BVC, Dhillon WS (2014) Heavy metal contamination in vegetables, fruits, soil and water - A critical review. Int J Agric Environ Biotechnol. 7:603-12.

Laidlaw MAS, Alankarage DH, Reichman SM, Taylor MP, Ball AS (2018) Assessment of soil metal concentrations in residential and community vegetable gardens in Melbourne, Australia. Chemosphere. 199:303-11.

Langkamp PJ (1985) Potential conflict between the coal and arable land resources in Australia: A case for corporate responsiveness. Environ Manage. 9:49-60.

Lechner AM, Baumgartl T, Matthew P, Glenn V (2016) The impact of underground longwall mining on prime agricultural land: A review and research agenda. Land Degrad Dev. 27:1650-63.

Lenth R (2019) Emmeans: Estimated Marginal Means, Aka Least-squares Means. R Package Version 1.3.3.

Lequeux H, Hermans C, Lutts S, Verbruggen N (2010) Response to copper excess in Arabidopsis thaliana: Impact on the root system architecture, hormone distribution, lignin accumulation and mineral profile. Plant Physiol Bioch. 48:673-82.

Maji MD, Chattopadhyay S, Kumar P, Saratchandra B (2005) In vitro screening of some plant extracts against fungal pathogens of mulberry (Morus spp.). Arch Phytopathol Pflanzenschutz. 38:157-64.

Manzoor S, Hameed A, Khan MA, Gul B (2017) Seed germination ecology of a medicinal halophyte Zygophyllum propinquum: responses to abiotic factors. Flora. 233:16370.

Márquez-García B, Márquez C, Sanjosé I, Nieva FJJ, Rodríguez-Rubio P, Muñoz-Rodríguez AF (2013) The effects of heavy metals on germination and seedling characteristics in two halophyte species in Mediterranean marshes. Mar Pollut Bull. 70:119-24.

McLaughlin MJ, Hamon RE, McLaren RG, Speir TW, Rogers SL (2000) Review: A bioavailability-based rationale for controlling metal and metalloid contamination of agricultural land in Australia and New Zealand. Aust J Soil Res. 38:1037-1086.

Nafiu A, Agbenin JO, Andreas B (2011) Phytoavailability, human risk assessment and transfer characteristics of cadmium and zinc contamination from urban gardens in Kano, Nigeria. J Sci Food Agric. 91:2722-30.

Nair PMG, Chung IM (2015) Study on the correlation between copper oxide nanoparticles induced growth suppression and enhanced lignification in Indian mustard (Brassica juncea L.). Ecotoxicol Environ Saf. 113:302-13.

National Environment Protection Measure (NEPM) (2013) Schedule B1: Guideline on investigation for soil and groundwater. Amended 2013. Viewed 22 May 2018 
<http://www.nepc.gov.au/system/files/resources/93ae0e 77-e697-e494-656f-afaaf9fb4277/files/schedule-b1guideline-investigation-levels-soil-and-groundwatersep10.pdf>

Olson PE, Fletcher JS (1999) Field evaluation of mulberry root structure with regard to phytoremediation. Bioremediat J. 3:27-34.

Panfili F, Manceau A, Sarret G, Spadini L, Kirpichtchikova T, Bert V, Laboudigue A, Marcus MA, Ahamdach N, Libert M (2005) The effect of phytostabilization on Zn speciation in a dredged contaminated sediment using scanning electron microscopy, X-ray fluorescence, EXAFS spectroscopy, and principal components analysis. Geochim Cosmochim Acta. 69:2265-2284.

Phillips ML, Murray BR (2012) Invasiveness in exotic plant species is linked to high seed survival in the soil. Evol Ecol. 14:83-94.

Qin F, Liu G, Huang G, Dong T, Liao Y, Xu X (2018) Zinc application alleviates the adverse effects of lead stress more in female Morus alba than in males. Environ Exp Bot. 146:68-76.

R Core Team (2019) R: A language and environment for statistical computing. $\mathrm{R}$ Foundation for Statistical Computing, Vienna, Austria. <https://www.Rproject.org/>.

Rafati M, Khorasani N, Moattar F, Shirvany A, Moraghebi F, Hosseinzadeh S (2011) Phytoremediation potential of Populus alba and Morus alba for cadmium, chromuim and nickel absorption from polluted soil. Int J Environ Sci. 5:961-70.

Rezek J, der Wiesche C, Mackova M, Zadrazil F, Macek T (2009) Biodegradation of PAHs in long-term contaminated soil cultivated with European White Birch (Betula pendula) and Red Mulberry (Morus Rubra) tree. Int J Phytoremediat. 11:66-81.

Rickson RJ, Deeks LK, Graves A, Harris JAH, Kibblewhite MG, Sakrabani R (2015) Input constraints to food production: the impact of soil degradation. Food Secur. 7:351-64.
Robertson AW, Trass A, Ladley JJ, Kelly D (2006) Assessing the benefits of frugivory for seed germination: the importance of the deinhibition effect. Funct Ecol. 20:5866.

Rojas RV, Achouri M, Maroulis J, Caon L (2016) Healthy soils: a prerequisite for sustainable food security. Environ Earth Sci. 75:1-10.

Rouillon M, Harvey PJ, Kristensen LJ, George SG, Taylor MP (2017) VegeSafe: A community science program measuring soil-metal contamination, evaluating risk and providing advice for safe gardening. Environ Pollut. 222:557-66.

Roy M, McDonald LM (2015) Metal uptake in plants and health risk assessments in metal-contaminated smelter soils. Land Degrad Dev. 26:785-92.

Sánchez-Rendón J, Reino-Molina J, Pernús-Alvarez $M$, Morales-Querol D, Martín-Martín G (2017) Effect of controlled conditions on the germination of five Morus alba L. varieties. Pastos y Forrajes. 40:264t.

Sethy S, Ghosh S (2013) Effect of heavy metals on germination of seeds. J Nat Sci Biol Med. 4, n/a.

Tóth G, Hermann T, Da Silva MR, Montanarella L (2016) Heavy metals in agricultural soils of the European Union with implications for food safety. Environ Int. 88:299-309.

Wang X, Sato T, Xing B, Tao S (2005) Health risks of heavy metals to the general public in Tianjin, China via consumption of vegetables and fish. Sci Total Environ. 350:28-37.

Xiao R, Wang S, Li R, Wang JJ, Zhang Z (2017) Soil heavy metal contamination and health risks associated with artisanal gold mining in Tongguan, Shaanxi, China. Ecotoxicol Environ Saf. 141:17-24.

Xiong Z (1998) Lead uptake and effects on seed germination and plant growth in a $\mathrm{Pb}$ hyperaccumulator Brassica pekinensis Rupr. B Environ Contam Tox. 60:285-91.

Zhang H, Zheng Feei Ma, Luo X, Li X (2018) Effects of mulberry fruit (Morus alba L.) consumption on health outcomes: A mini-review. Antioxidants. 7:69. 